\title{
Pemanfaatan Pekarangan Untuk Mendukung Ketahanan Pangan Masyarakat Desa Kali Upa
}

\author{
Ariance Yeane Kastanja1, Zeth Patty ${ }^{2}$, Zakarias Dilago ${ }^{3}$ \\ 1,2Fakultas Sains dan Kesehatan, Universitas Hein Namotemo \\ Email: kyeane@yahoo.com \\ Email: zethpatty4@gmail.com \\ 3Politeknik Perdamaian Halmahera \\ Email: zakariasdilago@gmail.com
}

Submitted: 12 Desember 2019 Revised: 26 Desember 2019 Accepted: 27 Desember 2019

\begin{abstract}
This community service activity was carried out in Kali Upa village, Tobelo Tengah sub-district, with the aim of increasing community knowledge and technology in the cultivation of yard plants, so that each family could strengthen food through these activities. The method used in this activity was counseling and continued with discussions with villagers as a process for transferring knowledge. This service is carried out as one of the village programs to improve the ability of the community to manage their yards of land so that the produce can be consumed as an additional source of family income. Optimizing the use of the yard by planting various types of agricultural crops can meet the food needs of the community also increase community income. In addition, food availability is one of the important factors in supporting community food security, because it is one indicator of welfare of life. Kali Upa Village is an area that has a flat topography and belongs to a group of narrow yard-medium yards, so that the use of plots can be done by combining various types of plants, including a combination of fruit plants, vegetable plants, food plants and other local plants which are adjusted with yard area.
\end{abstract}

Keywords: Kali Upa village, Community, Food Security, Yard

\begin{abstract}
Abstrak
Kegiatan pengabdian masyarakat ini dilakukan di Desa Kali Upa kecamatan Tobelo Tengah, dengan tujuan untuk meningkatkan pengetahuan dan teknologi masyarakat dalam budidaya tanaman pekarangan, sehingga setiap keluarga dapat memperkuat pangan melalui kegiatan tersebut. Metode yang digunakan dalam kegiatan ini adalah penyuluhan dan dilanjutkan dengan diskusi dengan masyarakat desa sebagai proses untuk mentransferkan pengetahuan. Pengabdian ini dilaksanakan sebagai salah satu program desa untuk meningkatkan kemampuan masyarakat dalam mengelola lahan pekarangannya sehingga hasil selain dapat dikonsumsi juga dapat dijadikan sebagai sumber tambahan pendapatan keluarga. Optimalisasi pemanfaatan pekarangan dengan menanami berbagai jenis tanaman pertanian dapat memenuhi kebutuhan pangan masyarakat, juga meningkatkan pendapatan masyarakat. Selain itu ketersediaan pangan merupakan salah satu faktor penting dalam mendukung ketahanan pangan masyarakat, karena merupakan salah satu indikator kesejahteraan hidup. Desa Kali Upa merupakan daerah yang memiliki topografi datar dan pekarangannya tergolong dalam kelompok pekarangan yang sempit - pekarangan sedang, sehingga pemanfaaatan pekarangan dapat dilakukan dengan mengkombinasikan berbagai jenis tanaman, diantaranya kombinasi antara tanaman buah-buahan, tanaman sayuran, tanaman pangan dan tanaman lokal lainnya yang disesuaikan dengan luasan pekarangan.
\end{abstract}

Kata Kunci: Desa Kali Upa, Masyarakat, Ketahanan Pangan, Pekarangan

\section{PENDAHULUAN}

Desa Kali Upa merupakan salah satu desa di kecamatan Tobelo
Tengah Kabupaten Halmahera Utara, dengan jumlah penduduk sebesar 750 jiwa yang sebagian 
besar bermata pencaharian sebagai petani, serta jumlah rumah tangga tani sebanyak $140 \quad$ KK (BPS Halmahera Utara, 2019).

Salah satu program yang dikembangkan oleh pemerintah Desa Kali Upa adalah pemanfaatan lahan pekarangan dengan berbagai jenis tanaman sehingga dapat dijadikan sebagai sumber pangan masyarakat. Program ini dilaksanakan dengan tujuan meningkatkan pengetahuan dan teknologi masyarakat dalam budidaya tanaman pekarangan, sehingga setiap keluarga dapat memperkuat pangan melalui kegiatan tersebut. Menurut Dwiratna, Widyasanti, \& Rahmah, (2016) menyatakan bahwa ketahanan pangan tidak hanya didukung oleh pemerintah tetapi juga penting melibatkan masyarakat secara aktif.

Pekarangan memiliki potensi yang besar dalam mendukung ketahanan pangan rumah tangga, karena jika dimanfaatkan secara optimal, dapat menjadi sumber gizi keluarga dalam hal pemenuhan vitamin dan mineral. Selain itu pemanfaatan pekarangan memberi beberapa manfaat seperti sumber pangan dan papan keluarga, sumber keanekaragaman tanaman, pengendali iklim mikro dan menciptakan lingkungan hidup yang optimal bari keluarga dan ternak yang dipelihara (Sudalmi \& Hardianti, 2018).

Hingga saat ini pemanfaatan pekarangan oleh masyarakat di Desa Kali Upa belum dilakukan secara optimal, padahal jika pekarangan rumah warga ditanami dengan berbagai jenis tanaman bisa memenuhi kebutuhan hidup sehari hari, selain itu juga dapat dijadikan sebagai tambahan penghasilan keluarga. Optimalisasi pemanfaatan pekarangan dengan menanami berbagai jenis tanaman pertanian dapat memenuhi kebutuhan pangan masyarakat juga meningkatkan pendapatan masyarakat. Hal ini sejalan dengan pendapat (Zulkarnaen, 2009) yang menyatakan bahwa pekarangan memiliki fungsi antara lain sebagai penghasil pangan tambahan, penghasil tambahan uang dan penghasil apotik hidup. Lebih lanjut dijelaskan bahwa jenis tanaman pekarangan yang diusahakan harus memenuhi komponen efisiensi produksi zat gizi yakni produksi dan kandungan gizi yang tinggi.

Berdasarkan penjelasan, maka kegiatan penyuluhan pemanfaatan pekarangan dilaksanakan bekerja sama dengan perguruan tinggi. Perguruan tinggi dilibatkan dalam program ini agar proses tranfer ilmu dan teknologi bagi masyarakat bisa tercapai. Selain itu dengan kegiatan penyuluhan yang dilakukan maka 
salah satu tridarma perguruan tinggi yakni pengabdian dapat dilaksanakan bagi masyarakat.

\section{METODE PELAKSANAAN}

Metode yang digunakan dalam kegiatan pengabdian ini adalah penyuluhan, diskusi dan pengenalan tentang bentuk-bentuk pemanfaatan pekarangan melalui gambar-gambar dan video sehingga mempermudah peserta memahami materi yang telah disampaikan. Penyuluhan sendiri diartikan sebagai upaya-upaya yang dilakukan untuk mendorong terjadinya perubahan perilaku pada individu, kelompok, komunitas, ataupun masyarakat agar mereka tahu, mau, dan mampu menyelesaikan permasalahan yang dihadapi (Amanah, 2007).

Penyuluhan yang disampaikan kepada peserta dengan tujuan antara lain:

a) Menyampaikan informasi dan pengetahuan bagi peserta tentang ketahanan pangan

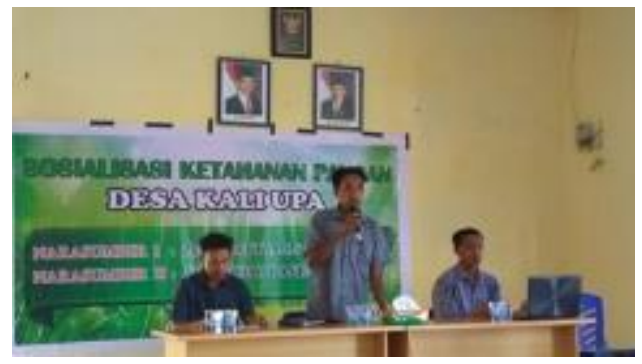

Gambar 1. Acara Pembukaan oleh Kepala Desa Kali Upa 


\section{Ketahanan Pangan}

Penyampaian materi tentang ketahanan pangan disampaikan kepada masyarakat sehingga pengetahuan tentang konsep ketahanan pangan dapat dipahami. Materi yang disampaikan mencakup ketersediaan pangan, akses pangan, dan pemanfaatan pangan. Pangan merupakan salah satu faktor yang berperan penting dalam kehidupan manusia. Ketahanan pangan didefenisikan sebagai suatu keadan terpenuhi dan terjaminnya kebutuhan pangan bagi setiap anggota keluarga baik dari segi mutu, aman, merata dan terjangkau. Ketersediaan pangan merupakan salah satu faktor penting dalam mendukung ketahanan pangan masyarakat, karena merupakan salah satu indikator kesejahteraan hidup. Hal ini sejalan dengan pendapat

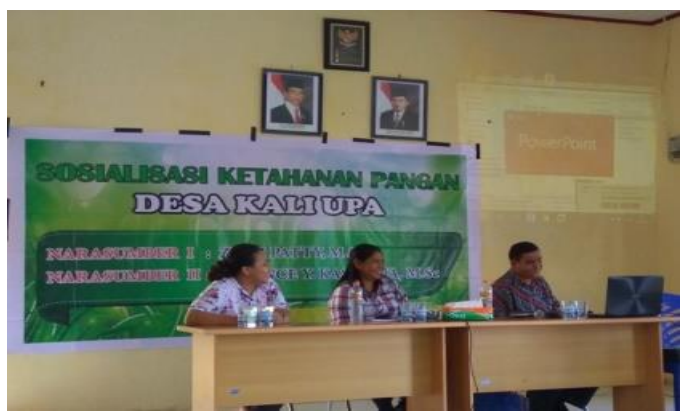

Gambar 2. Penyampaian materi oleh narasumber
Mariyani, Prasmatiwi, \& Adawiyah, (2017) yang menyatakan; Rumah tangga yang memiliki ketersediaan pangan ditandai dengan banyaknya jumlah pangan yang tersedia bagi keluarga. Lebih lanjut penjelasan tentang aksesbilitas dan pemanfaatan pangan juga disampaikan kepada masyarakat. Aksesbilitas pangan mencakup ketersediaan pangan dan kemampuan seseorang untuk mendapatkan pangan. Kemampuan untuk memperoleh pangan merupakan salah satu masalah yang dihadapi oleh masyarakat, termasuk daya beli yang rendah (Rachman, 2010).

Penyampaian materi penyuluhan pemanfaatan pekarangan oleh salah satu narasumber disajikan pada gambar 2 Berikut

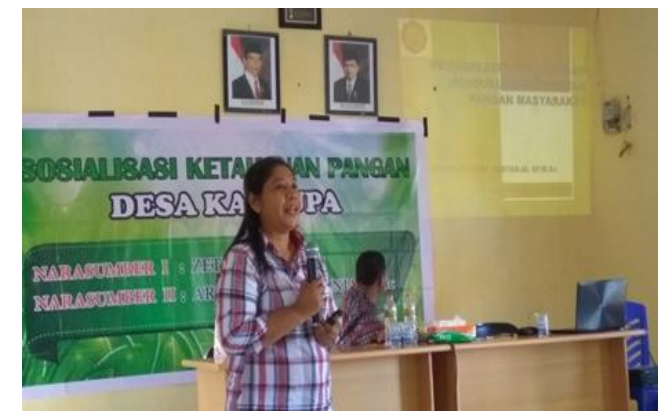

pekarangan terdiri dari campuran beberapa tanaman pertanian baik tanaman hortikultura, tanaman perkebunan dan tanaman pangan. Pada umumnya tanaman hortikultura merupakan jenis tanaman yang paling banyak 
ditanam di lahan pekarangan (Murtiati \& Fitriani Nur, 2015)

Berdasarkan hasil yang diperoleh, pemanfaatan pekarangan oleh masyarakat desa Kali Upa belum dilakukan secara optimal, Hal ini terlihat pada lahan pekarangan warga kebanyakan dibiarkan kosong tanpa ditanami dengan tanaman pertanian, hanya berupa lahan yang ditumbuhi rumput. Masyarakat lebih banyak mengusahakan lahan pertaniannya pada kebun warga yang letaknya berada di belakang desa. Melalui penyuluhan ini masyarakat mendapat gambaran tentang manfaat mengelola lahan pekarangan mereka.

Pengenalan pola pertanian pada lahan pekarangan berupa tanaman campuran disampaikan kepada masyarakat, antara lain kombinasi antara tanaman buah-buahan dengan tanaman sayur-sayuran, tanaman buah-buahan dengan tanaman obat-obatan, sehingga memberi manfaat ekonomis bagi masyarakat. Jenis tanaman sayuran yang diusahakan dipilih tanaman sayuran berumur 1-3 bulan seperti tanaman sawi, kangkung cabut,

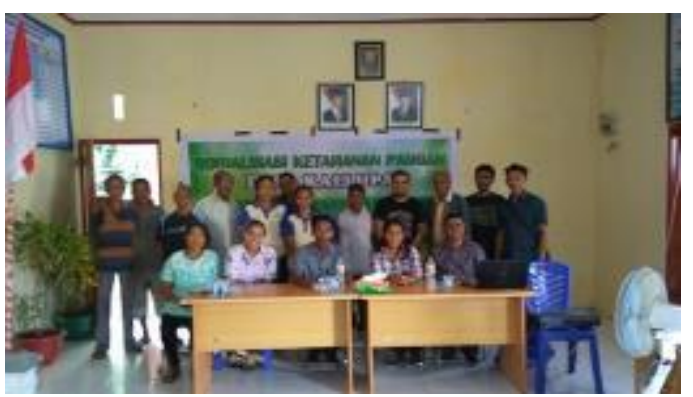

bayam, dll. Selain itu jenis tanaman sayuran yang dapat dimanfaatkan keluarga seperti tomat, cabe, dan jenis tanaman rempah-rempah juga dapat diusahakan.

Desa Kali Upa merupakan daerah yang memiliki topografi datar dan tergolong dalam kelompok pekarangan yang sempit - pekarangan sedang. Model budidaya yang cocok untuk dikembangkan untuk pekarangan lahan sempit adalah vertikultur, polibag/pot. Sedangkan untuk pekarangan sedang model budidaya yang cocok dikembangkan adalah polibag / pot, tanam langsung, bedengan, dan dapat dikombinasikan dengan kolam ikan, kandang ternak, sedangkan jenis tanaman yang dapat dikembangkan adalah Sayuran: Cabe, kenikir, terong, tomat, kecipir, kacang panjang, buncis, katuk, kelor, labu kuning. Tanaman obat keluarga (toga): Jahe, kencur, lengkuas, kunyit, temulawak, sirih.

Kegiatan penyuluhan dan diskusi, diakhiri dengan foto bersama narasumber, peserta dan perangkat desa disajikan pada gambar 3 berikut.

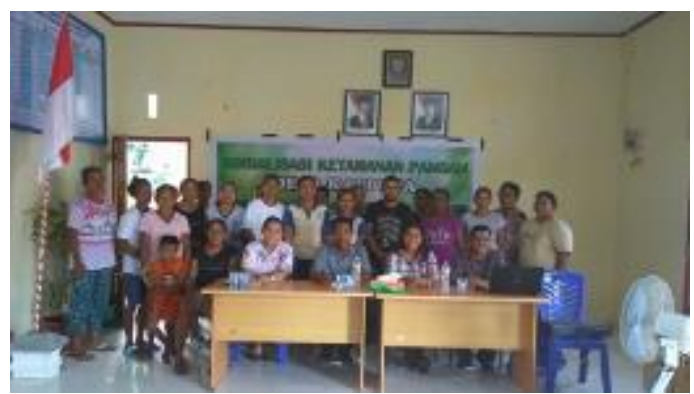

Gambar 3. Foto Bersama Peserta Kegiatan Penyuluhan 
Kategori basis komoditas dan

Purwantini, (2012) disajikan pada model budidaya pekarangan

tabel 1. Berikut:

menurut Ashari, Saptana, \&

Tabel 1. Basis Komoditas dan Contoh Model Budidaya

Rumah Pangan Lestari Menurut Kelompok Lahan Pekarangn Pedesaan

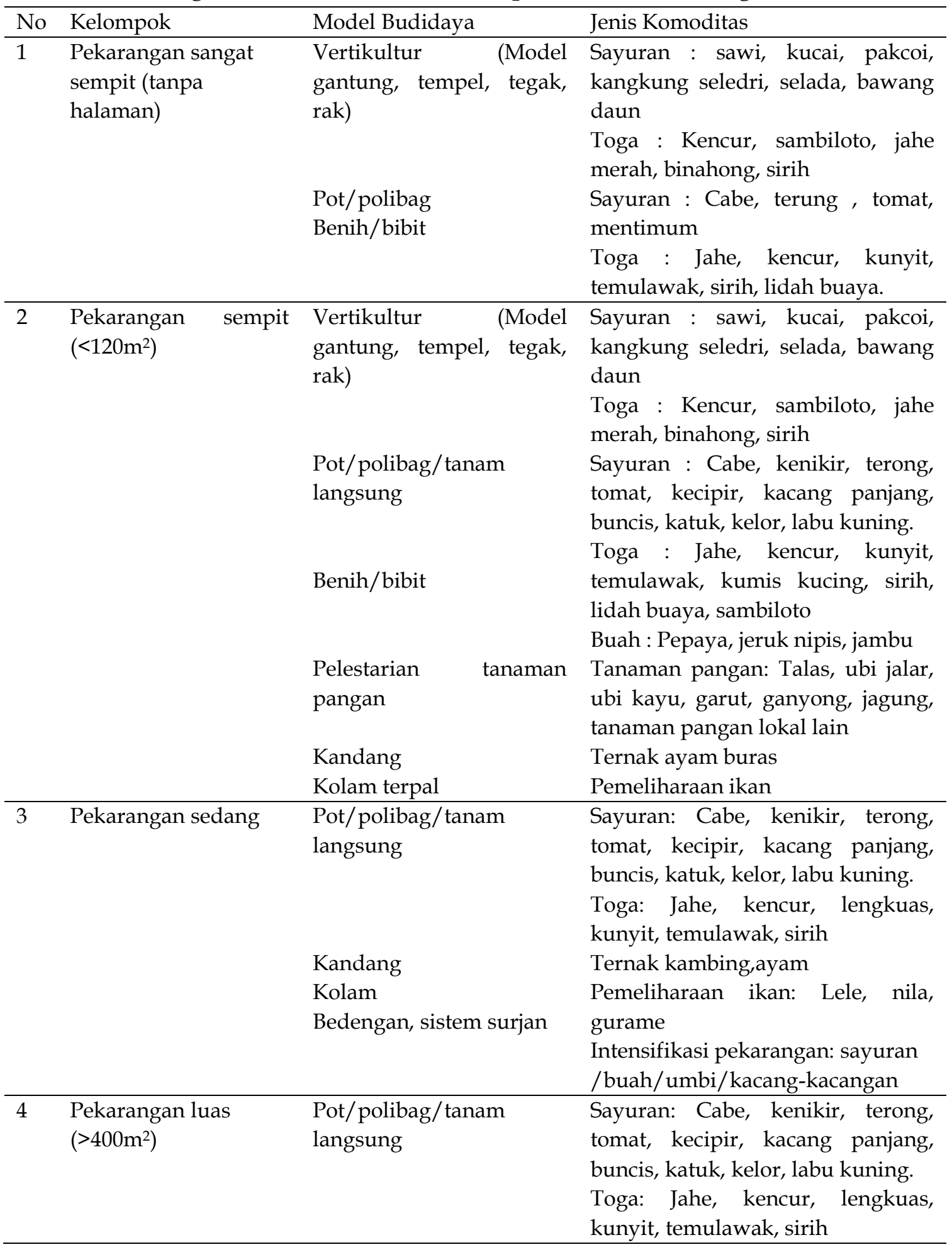




\begin{tabular}{ll}
\hline & Ternak kambing,domba,ayam \\
Kandang & Pemeliharaan ikan: Lele, nila, \\
Kolam & gurame \\
Bedengan, & Intensifikasi pekarangan: \\
sistem surjan & sayuran/buah/umbi/kacang- \\
& kacangan \\
\hline
\end{tabular}

Berdasarkan tabel tersebut di atas, maka Pemanfaaatan pekarangan dilakukan dengan mengkombinasikan berbagai jenis tanaman, diantaranya kombinasi antara tanaman buah-buahan, tanaman sayuran, tanaman pangan dan tanaman lokal lainnya serta disesuaikan dengan luas pekarangan yang dimiliki masyarakat.

Hal ini sesuai dengan pendapat Junaidah, P.Suryanto, \& Budiadi, (2015) bahwa pekarangan memiliki kegunaan seperti sumber pangan, antara lain sayuran, umbi-umbian, rempah, ternak, kayu bakar dan lain lain. Lebih lanjut Solihin, Sandrawati, \& Kurniawan, (2018) menyatakan bahwa pekarangan memiliki kegunaan sebagai sumber pendapatan, sumber oksigen, sumber estetika dan tempat kegiatan. Selain kombinasi jenis tanaman, pengetahuan tentang teknik budidaya tanaman juga diperkenalkan kepada masyarakat terutama tentang budidaya tanaman sayuran mencakup jenis-jenis sayuran dan syarat tumbuh, pengolahan tanah, cara tanam, pemupukan, pengendalian hama penyakit, dan pengendalian gulma.

Pekarangan rumah masyarakat desa yang ditanami beberapa jenis tanaman, disajikan pada Gambar 4 berikut:
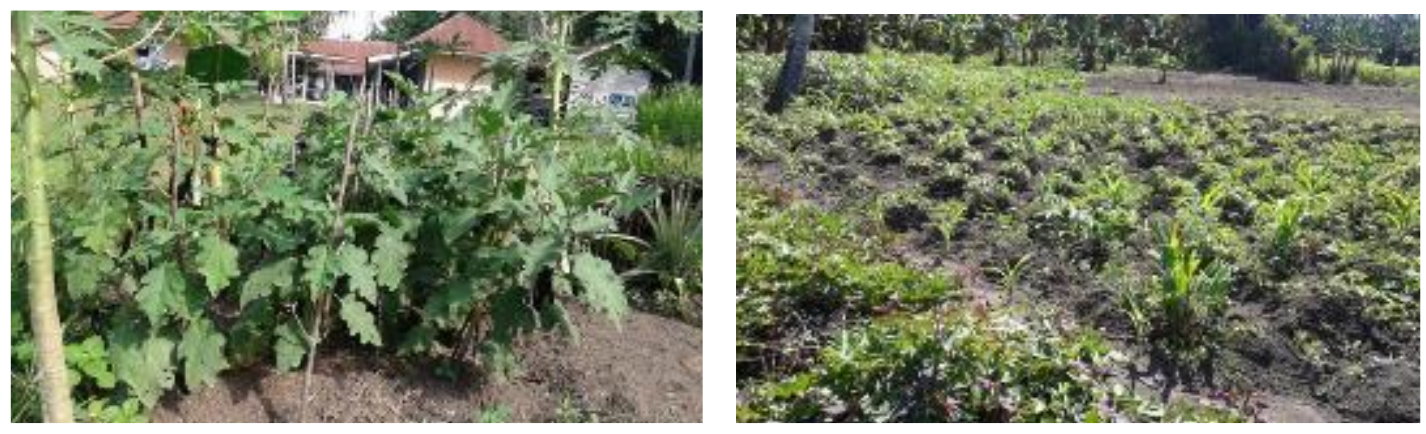

Gambar 4. Pekarangan Rumah Masyarakat

\section{PENUTUP}

1. Penyuluhan

pemanfaatan pekarangan dapat meningkatkan pengetahuan masyarakat terutama dalam memilih jenis tanaman, syarat tumbuh dan teknik budidaya. 
2. Pemanfaatan pekarangan dapat meningkatkan ketersediaan pangan masyarakat dan dapat dijadikan sebagai sumber pendapatan.

\section{DAFTAR PUSTAKA}

Amanah, S. (2007). Makna Penyuluhan dan Transformasi Perilaku Manusia. Jurnal Penyuluhan, 3(1), 5. https://doi.org/10.25015/ penyuluhan.v3i1.2152

Ashari, Saptana, \& Purwantini, T. B. (2012). Potensi dan Prospek Pemanfaatan Lahan Pekarangan Untuk Mendukung Ketahanan Pangan. Forum Penelitian Agro Ekonomi, 30(1), 13-30.

BPS Halmahera Utara. (2019). Tobelo Tengah Dalam Angka 2019 (1102001.8205041 No. 82050.1914). Tobelo.

Dwiratna, N. P. S., Widyasanti, A., \& Rahmah, D. M. (2016). Pemanfaatan Lahan Pekarangan Dengan Menerapkan Konsep Kawasan Rumah Pangan Lestari. Dharmakarya Jurnal Aplikasi Ipteks Untuk Masyarakat, 5(1), 34-37. https://doi.org/10.2134/jeq200 4.0288

Junaidah, P.Suryanto, \& Budiadi. (2015). Komposisi Jenis dan Fungsi Pekarangan (Studi kasus desa Giripurwo, Kecamatan Girimulyo, DI Yogyakarta). Jurnal Hutan Tropis, 4(1), 77. https://doi.org/10.20527/jht.v4 i1. 2884
Mariyani, S., Prasmatiwi, F. E., \& Adawiyah, R. (2017). Ketersediaan Pangan Dan Faktor-Faktor Yang Mempengaruhi Ketersediaan Pangan Rumah Tangga Petani Padi Anggota Lumbung Pangan Di Kecamatan Ambarawa Kabupaten Pringsewu. JIIA, 5(3), 304-311.

Murtiati, S., \& Fitriani Nur. (2015). Pekarangan Sebagai Pendongkrak Pendapatan Ibu Rumah Tangga di Kabupaten Boyolali. In Jatnika (Ed.), Inovasi Hortikultura Pengungkit

Peningkatan Pendapatan Rakyat (pp. 278-282). Bogor: IAARD Press.

Rachman, H. P. S. (2010). Aksesibilitas Pangan: Faktor Kunci Pencapaian Ketahanan Pangan di Indonesia. Jurnal Pangan, 19(2), 147-156. https://doi.org/10.33964/JP.V1 9I2.128

Solihin, E., Sandrawati, A., \& Kurniawan, W. (2018). Pemanfaatan Pekarangan Rumah Untuk Budidaya Sayuran Sebagai Penyedia Gizi Sehat Keluarga. Journal of Chemical Information and Modeling, 53(9), 1689-1699. https://doi.org/10.1017/CBO9 781107415324.004

Sudalmi, E. S., \& Hardianti, J. S. (2018). Usaha Pelestarian Lingkungan Hidup Melalui 


\section{Penganekaragaman Tanaman}

Pekarangan. Adiwidya, II(2),

153-158.

Zulkarnaen, H. (2009). Dasar-Dasar

Hortikultura. (R. Rahmatica, Ed.)

(Satu). Jakarta: Bumi Aksara. 